\title{
Over prescription of Proton Pump Inhibitors on discharge of Medical Inpatients
}

\author{
SARMISTHA BISWAS, ${ }^{1}$ ABM ABU SUFIAN, ${ }^{2}$ PRODIP KUMAR SARKAR, ${ }^{3}$ MOSTOFA KAMAL CHOWDHURY ${ }^{3}$ \\ JOYBAER ANAM CHOWDHURY, ${ }^{4}$ CHANDRA SHEKHAR BALA,${ }^{5}$ MD. RAFIQUL ISLAM, ${ }^{1}$ HAM NAZMUL AHASAN, ${ }^{6}$ \\ MA KASHEM ${ }^{7}$
}

\begin{abstract}
:
Background: Proton pump inhibitors (PPIs) are the drugs used to treat and prevent acid peptic conditions. Their efficacy and safety profile has led to injudicious prescription of these drugs exposing patients to various potential risks and increased healthcare expenditure.

Methodology: A retrospective observational study was done from $10^{\text {th }}$ January to $24^{\text {th }}$ January, 2015 in Medicine Indoor in a tertiary care hospital to determine the trend of prescribing PPIs on discharge of Medical inpatients.

Result: We found II7 patients were discharged in the study period; 83 were male and 34 were female. Among them 102 (87. I7\%) were prescribed PPIs on their discharge. Mean age was 44.79 years. Among the study population only 29 patients (28.5\%) truly needed PPIs during their discharge. The mean duration of prescribed PPIs was 28 days.

Conclusion: Amore rational prescription of PPI during discharge will have better impact on patient safety and health care expenditure.
\end{abstract}

Key words: Proton pump inhibitors (PPIs); prescription; over prescription, medical inpatients

\section{Introduction:}

Proton Pump Inhibitors (PPI) are widely used anti ulcerant drugs. They are used for acid- peptic conditions like peptic ulcer, dyspepsia, gastro-esophageal reflux, stress ulcer prophylaxis etc., ${ }^{1,2}$ PPIs are one of the most widely prescribed drug worldwide. There is a common belief about its higher safety profile. But recently, evidence is mounting against its safety. Potential harms like hypergastrinemia, gastrointestinal as well as respiratory infections and nutritional deficiencies are being found in long term PPI users. We have noticed the over prescription of PPIs in both our inpatient and outdoor settings. PPIs are now available as over the counter (OTC) drug in our country. So we tried to measure the over prescription of PPIs on discharge of Medical Inpatients from a tertiary care hospital in Dhaka, Bangladesh.

1. Assistant Professor, Medicine, Dhaka Medical College, Dhaka.

2. Honorary Medical Officer, Medicine, Dhaka Medical College, Dhaka.

3. Indoor Medical Officer, Medicine, Dhaka Medical College, Dhaka.

4. Assistant Register, Medicine, Dhaka Medical College, Dhaka.

5. Junior Consultant, Medicine. National Institute of Neuroscience, Dhaka.

6. Professor, Medicine, Popular Medical College, Dhaka.

7. Associate professor, Medicine, Dhaka Medical College, Dhaka.

Corresponding author: Dr. Sarmistha Biswas. Assistant Professor, Dept. of Medicine, Dhaka Medical College, Dhaka. E-mail: sarmibiswas365@gmail.com.

\section{Methodology:}

This is a prospective cross sectional observational study. It was carried out in Dhaka Medical college Hospital from 10.01.2015 to 19.01.2015. We audited the discharge certificates of all the units of Internal Medicine department only. Surgery, Gynaecology ward and wards of other subspecialties were excluded. The demographic details of patients', cause of admission into hospital and drugs prescribed on discharge including PPI with duration were recorded. Statistical analysis was done using SPSS version 17.

\section{Results:}

During the audit period total 117 discharge certificates were collected from different wards of the department of Medicine. Out of 117, 102 discharge certificates (87.17\%) had different Proton Pump Inhibitors with different duration. Only 15 discharge certificates did not bear any PPI. Mean age of the patients were 44.79 years ranging from 12 to 94 years. Of 117 patients, 83 were male and 34 were female (28.3\%).Among the male patients, $74(89 \%)$ received PPI; $28(82 \%)$ of female patients had received PPI [Table-I]. Regarding indication, 26 patients (18.9\%) received PPI for drug induced Peptic Ulcer Prevention, 3 patients $(2.8 \%)$ received for Peptic Ulcer [Table-2]. On the audited discharge certificates PPI were prescribed for different duration ranging from 5 days to 60 days [Table-III]. Figure 1 shows that patients with urinary tract infections were the highest population among infective cases who got PPIs on discharge (40\%). We found various preparations of PPI in practice. Omeprazole was the most prescribed PPI [97 discharge certificates (95.3\%)]. Pantoprazole and Esomeprazole were found in 2 prescriptions each (1.9\%). Rabeprazole was prescribed in one discharge certificate $(0.9 \%)$ [Table-IV] 
Table-I

Characteristics of cohort: PPI users vs. patients who were not prescribed PPI $(n=117)$

\begin{tabular}{lccc}
\hline & $\begin{array}{c}\text { Received PPI on } \\
\text { discharge }\end{array}$ & $\begin{array}{c}\text { Did not received PPI } \\
\text { on Discharge }\end{array}$ & P value \\
\hline Total patients & $102(87.17 \%)$ & $15(12.83 \%)$ & 0.9 \\
Mean age (Years) & $44.79+18.03$ & $43.87+19.03$ & 0.0004 \\
Sex: $\quad$ Male $(\mathrm{n} 1=83)$ & $74(89 \%)$ & $9(11 \%)$ & $6(18 \%)$ \\
\hline$\quad$ Female $(\mathrm{n} 2=34)$ & $28(82 \%)$ & & \\
\hline
\end{tabular}

Table-II

Conditions where PPI was prescribed as per discharge certificate $(n=102)$

\begin{tabular}{|c|c|c|}
\hline Rating of Indication of PPI & Presumed reason for recommendation of PPI & Number \\
\hline $\begin{array}{l}\text { Documented Indication } \\
\mathrm{n} 1=29(28.5 \%)\end{array}$ & $\begin{array}{l}\text { Ischemic Stroke on Aspirin } \\
\text { Peptic Ulcer (endoscopy proven) } \\
\text { IHD on Aspirin } \\
\text { Chronic rheumatic heart disease on Warfarin } \\
\text { Rheumatic Arthritis on steroid } \\
\text { Acute Transverse Myelitis on Steroid } \\
\text { Tubercular Pleural Effusion on steroid } \\
\text { Acute Glomerulonephritis on steroid }\end{array}$ & $\begin{array}{l}12 \\
03 \\
07 \\
03 \\
01 \\
01 \\
01 \\
01\end{array}$ \\
\hline $\begin{array}{l}\text { No documented adequate } \\
\text { indication } \\
\mathrm{n} 2=73(71.5 \%)\end{array}$ & $\begin{array}{l}\text { Infections } \\
\text { Chronic Liver Disease } \\
\text { Uncontrolled Diabetes } \\
\text { Psychiatric disorders } \\
\text { COPD and Bronchial Asthma } \\
\text { intestinal obstruction } \\
\text { Malignancy } \\
\text { Hemorrhagic Stroke } \\
\text { Neurological disease other than stroke* } \\
\text { Chronic Kidney Disease } \\
\text { Hematological } \\
\text { Dilated Cardiomyopathy }\end{array}$ & $\begin{array}{l}25 \\
03 \\
07 \\
06 \\
05 \\
03 \\
06 \\
03 \\
03 \\
05 \\
06 \\
01\end{array}$ \\
\hline
\end{tabular}

*1 case of drug induced extrapyramidal syndrome and 2 cases of primary epilepsy.

$£ .1$ case each-Aplastic anemia, Hemophilia, Iron deficiency anemia, HbE disease, Non Hodgkins Lymphoma, Myelodysplastic syndrome.

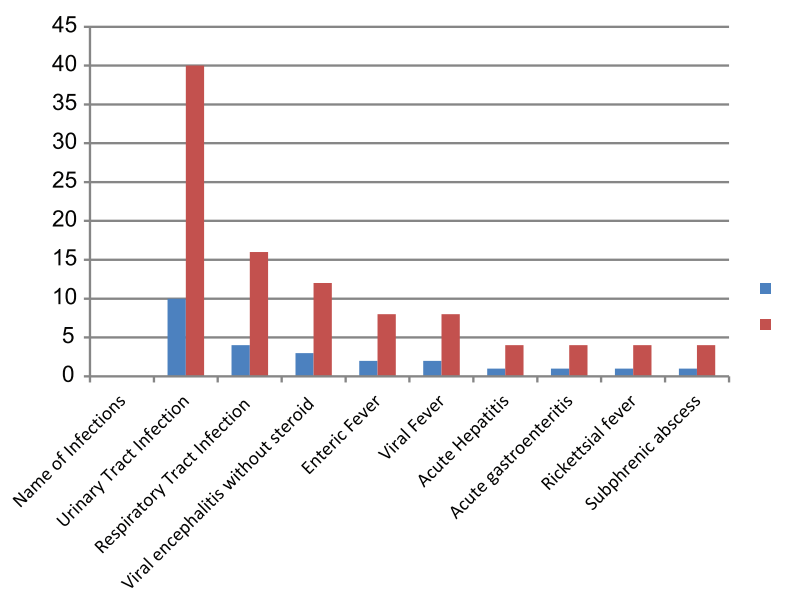

Fig.-1: Types of infection who received PPIs : $(n=25)$
Table-III

Duration of PPI prescribed (in days)

\begin{tabular}{lcc}
\hline Duration in days & Frequency & Percentage (\%) \\
\hline $1-14$ & 22 & 20.75 \\
$15-29$ & 37 & 34.91 \\
$30-44$ & 34 & 32.08 \\
$>=45$ & 13 & 12.26 \\
\hline
\end{tabular}


Table-IV

Types of PPI prescribed in the study population.

\begin{tabular}{lcc}
\hline Types of PPI & Frequency & Percentage $\%$ \\
\hline Omeprazole & 97 & 95.3 \\
Pantoprazole & 2 & 1.9 \\
Esomeprazole & 2 & 1.9 \\
Rabeprazole & 1 & 0.9 \\
\hline Total & 102 & 100 \\
\hline
\end{tabular}

\section{Discussion:}

In our study we found $102(87.17 \%)$ of study population were prescribed PPIs on their discharge though only 29 (28.5\%) patients were truly needed PPIs. Rest (71.5\%) are inappropriately prescribed PPIs, which is consistent with Muhammed Haroon et al. ${ }^{3}$ Though the guidelines recommend PPIs for a few indications, we found a significant percentage in their discharge paper ${ }^{4}$. It can be said that patients with no clinical indication to use PPIs are only exposed to the risks of these drugs. ${ }^{5}$ In our study we found males were more likely to receive than females, not consistent to the study done by Haroon et al and Brandhagen et al. ${ }^{6}$ PPIs were prescribed in certain infections like urinary tract infections $(40 \%)$, respiratory tract infections (16\%), acute gastroenteritis (\%) and enteric fever (12\%). A case controlled study done by Gulmez et al found that there was an observed fivefold increased risk of development of community acquired pneumonia with initiation of PPI within a week prior to diagnosis. ${ }^{7}$ Inappropriate prescribing of PPIs may also lead to Clostridium difficle associated diarrhoea and increased risk of hip fractures. ${ }^{8}$ In our study The cumulative percentage of patients prescribed PPIs twice daily for up to 29 days was $55.66 \%$ and $32.08 \%$ for the duration of 30 to 44 days. A randomized double-blind trial done by Niklasson et al ${ }^{9}$ found that $44 \%$ of the subjects in PPI therapy group who received PPI once daily for 28 days, developed dyspepsia compared with $9 \%$ of placebo group ( $\mathrm{p}$ value $<0.01$ ). It suggests an association of PPI discontinuation and rebound acid hyper secretion. Similar trial over eight weeks of therapeutic period yielded $22 \%$ of subjects reported peptic symptoms like dyspepsia, heartburn and regurgitation at 10 to 12 weeks post therapy. ${ }^{10}$ So it can be said that the over prescription of PPIs found in our study population may lead to many unwanted side effects. The mostly prescribed PPI was Omeprazole; which worth taka 5 on an average; so it takes tk300 for a single patient who takes Omeprazole twice daily for a month. Undoubtedly it is an extra expenditure for the poor population of Bangladesh. PPIs fall only behind the total cost expenditure worldwide, estimated at over US dollar 11 billion annually in USA and 2 billion euro in Britain. ${ }^{11.12}$ In a nutshell it can be said that as long as the drug expenditure and safety concerns are the most important negative points, PPIs should be judiciously prescribed in a patient. Rational prescription of PPI not only reduces unnecessary health care expenditure but also positively ensures health safety.

\section{Conclusion:}

We have found that $71.5 \%$ of our study population were inappropriately prescribed PPIs during their discharge, which is really alarming. As it was a cross sectional study, potential long term adverse effects could not be assessed. Further large scale, randomized, prospective study is needed to quantify the hazard due to over prescription of PPIs and a care plan remains crucial in this regard.

\section{Conflict of interest: None}

\section{References:}

1. Nicki R. Colledge, Brian R. Walker, Stuart H. Ralston. Davidsons Principle of Medicine 2010;21:870-76.

2. Grube RR, May DB. Stress Ulcer Prophylaxis in hospitalized patients not in intensive care units. Am J Health Syst Pharm 2007;64 (13):1396-1400.

3. Muhammed Haroon, Faiza Yasin et al. Inappropriate use of proton-pump inhibitors among medical inpatients: a questionnaire based observational study. J R soc Med Sh Rep.2013;4:36.

4. North of Tyne Area Prescribing Committee PPI- Guideline 2015.

5. Joel J Hydelberg, Andrea H Kim, Robert Channg et al. Over utilization of Proton Pump Inhibitors. What the Clinician needs to know.Ther Adv Gastroenterol.2012;5 (4):219-232.

6. Brandhagen DJ, Pheley AM, Onstad GR, Freeman ML, Lurie N. Omeprazole use at an urban country teaching hospital. J Gen Intern Med 1995;10:513-15.

7. Guimez S. E, Holm A, Frederiksen. H et al. Use of proton pump inhibitors and the risk of community acquired pneumonia: a population based case-control study. Arch Int Med. 2007;167:950-55.

8. Dick Ahrens, Jean Francois Chenol, Gesa Behrens, Thomas Grimmmann, Michael M. Kohen. Appropriateness of treatment recommendations for PPI in hospital discharge letters. Euro J Prarmacol.2010;66:1265-71.

9. Niklasson a, Lindstrom L, simres $\mathrm{M}$ et al. Dyspeptic symptom development after discontinuation of a proton pump inhibitor: a double-blind placebo-controlled trial. Am J Gastroenterol. 2010;105:1531-37.

10. Reimer C, Sondergaard B, Hilsted L, Bytzer, P. Proton pump inhibitor therapy induces acid related symptoms in healthy volunteers after withdrawal of therapy. Gastroenterology 2009; $137: 80-87$.

11. Drug topics (2011) and Pharmacy Facts and Figures. Available at: http;//drug topics. Modernmedicine.com/ drugtopics/article/articlelist.jsp?category bl=7604.

12. Fargecs, I., Loganayagam, A. Overprescribing proton pump inhibitors is expensive and not evidence based. BMJ 2008;336:2-3. 